\title{
Medieval reclamation and colonization of marginal land on Romney Marsh Luke Barber
}

Since 1991 the UCL Field Archaeology Unit (UCL.FAU) has been investigating the settlement pattern and landscape history of part of Romney Marsh in Kent, revealed by gravel extraction at Lydd Quarry. The project manager describes the work and shows how it is contributing to our knowledge of rural life in medieval England.

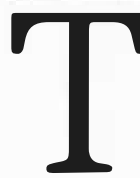

$\checkmark$ structures of rural England. This is particularly the case when exten sive areas can be subjected to relatively intensive archaeological investigation, and even more so when the settlement pattern can be traced from its initial establishment. The work by the UCLFAU at Lydd Quarry (Fig. 1) has yielded information about not only the medieval settlement pattern but also about a whole landscape prior to its destruction by gravel extraction. ${ }^{2}$ Romney Marsh is one of the three largest areas of marshland in England (the Levels) and it has a very complex history that has seen dramatic changes to its internal features as well as to its coastline. ${ }^{3}$ Although archaeological evidence indicates that the marsh was exploited on a seasonal basis from at least the early Bronze Age, it is not until the medieval period that large-scale permanent settlement becomes other two being the Fens and the Somerset

apparent after a period of systematic reclamation and consolidation.

\section{The site and the excavation strategy}

The site at Lydd Quarry is situated on silty clays that overlie ridges of Dungeness shingle, at an average elevation of $2.4-2.6 \mathrm{~m}$ above mean sea level. The first stage of archaeological work, at Lydd 1 (Fig. 2), was undertaken in late 1991, and by 1999 ten further stages of fieldwork had been completed. The strategy for excavating the site posed an initial problem because the archaeological remains were so abundant that a totally detailed study was neither practicable nor financially viable. Kent County Council, in consultation with the UCLFAU, therefore proposed a strategy that gave priority to obtaining a complete plan of the archaeological landscape. This was to be followed by excavations of selected areas to ascertain the form, function, date and development of the ditched field system, which is a major feature of the site and of its associated settlements. As a result of adopting this strategy it has been possible

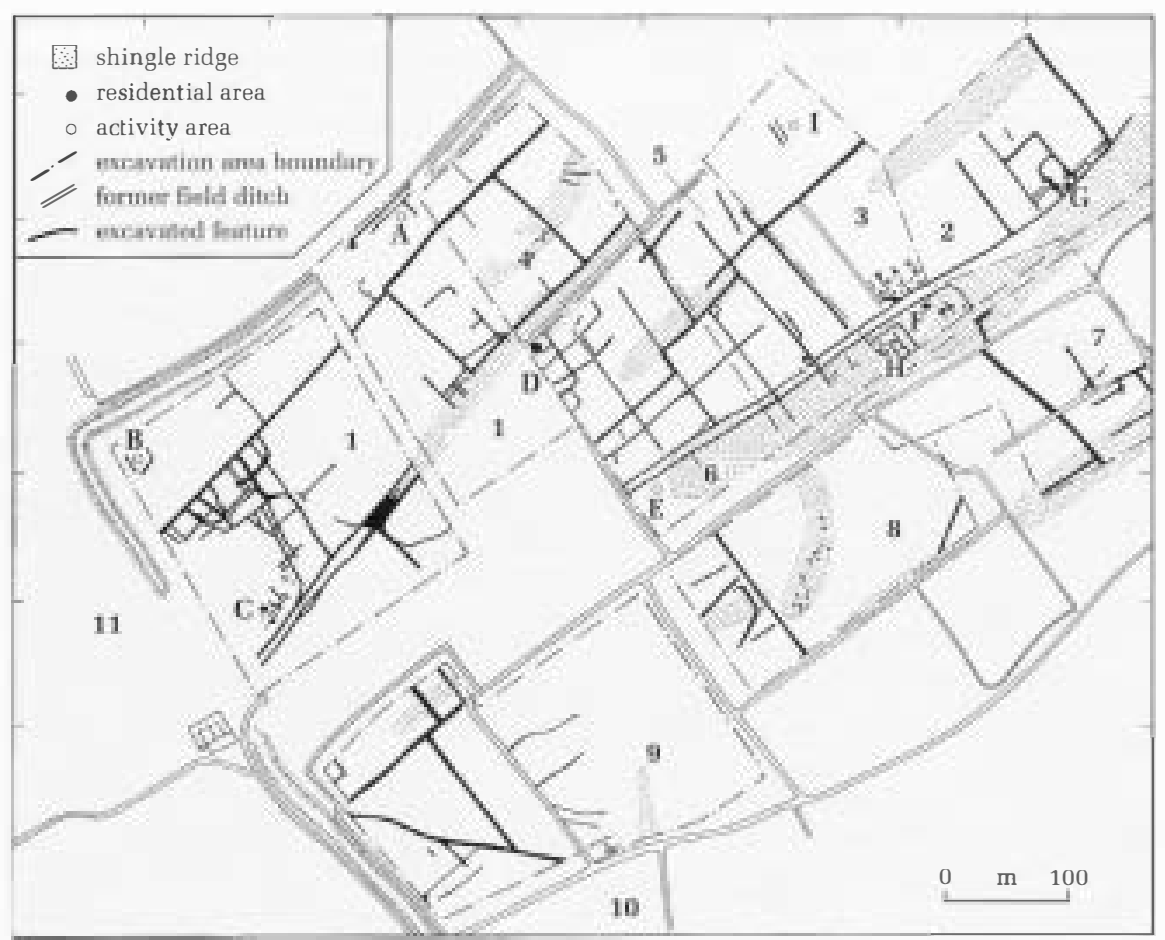

Figure 2 Plan of the excavated field system at Lydd Quarry (excavation stages 1-11) showing the location of residential and activity areas $(A-I)$.

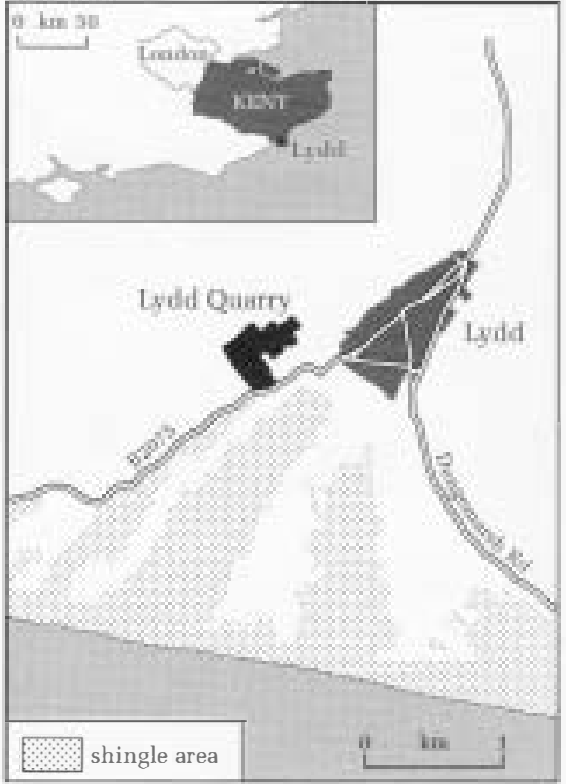

Figure 1 Location of Lydd Quarry, Kent.

to record a large area of the medieval landscape (Figs 2, 3 and 4).

\section{The field system}

The excavations are revealing a large area of medieval fields of varying sizes, demarcated by a system of drainage ditches. There is evidence for at least two diverging tracks running between the fields, each bounded by ditches. These link several residential areas, but the origins and ultimate destinations of the tracks are at present unknown. The field system itself consisted of a patchwork of square or rectangular fields, of varying sizes, roughly aligned with the natural shingle ridges of the area. The modern field boundaries that were still in existence prior to gravel extraction of ten show a direct correlation with the alignment of the earlier medieval system. The modern boundaries therefore represent an evolved pattern that has developed through a process of continuing change since its initial formation in the medieval period.

The final infilling of many of the ditches took place between the fourteenth and sixteenth centuries AD, although a few at Lydd 7 (Fig. 2) were infilled during the eighteenth and nineteenth centuries. Several ditches that enclosed small areas within fields, but are not associated with occupation, are also apparent. They may have been temporary enclosures for the production of thorn (hawthorn or whitethorn) used in building earthen walls for marsh reclamation, ${ }^{4}$ or alternatively they may have been used to control livestock.

\section{Settlement}

By late 1999 we had examined an area in excess of 18 ha, within which we found one probable (Fig. 2: D) and three definite (Fig. 2: C, F, G) residential areas and five activity areas (Fig. 2: A, B, E, H, I). The three 


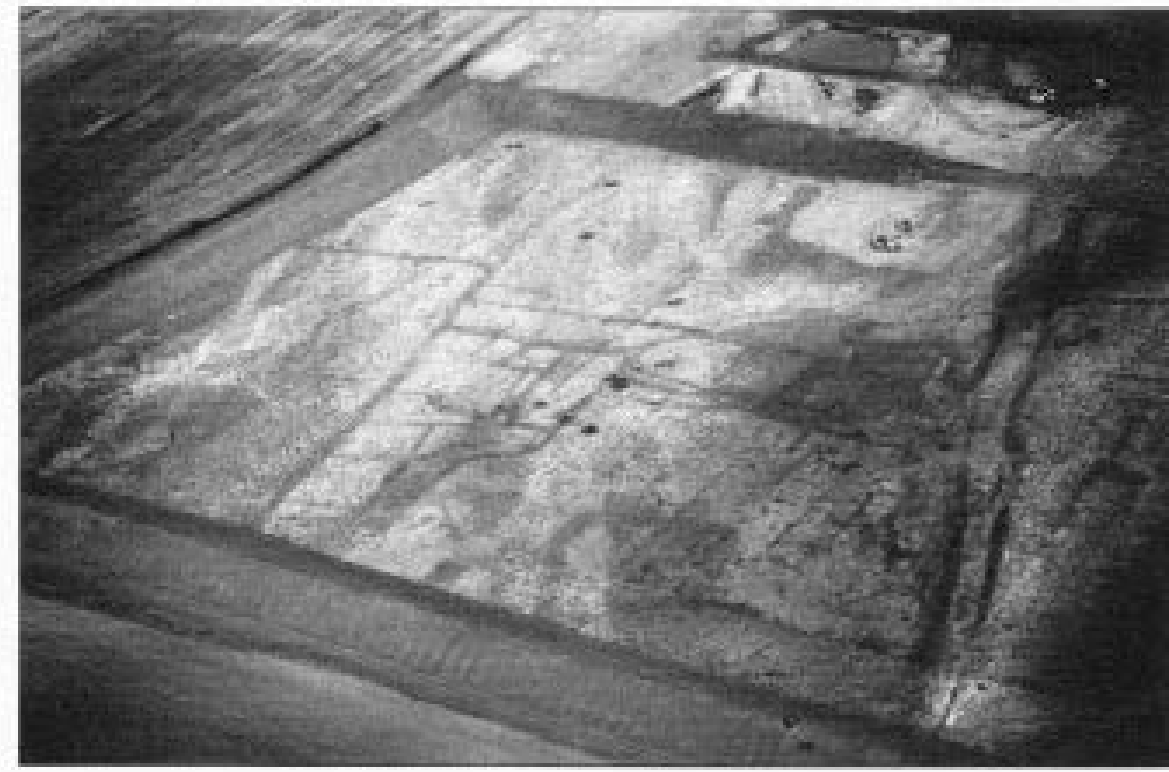

Figure 3 Aerial view of the field system at Lydd 1, looking northeast, October 1991.

definite residential areas are adjacent to one or other of the two trackways. The locations of other sites (e.g. B in Lydd 1), where other activities took place, was not constrained in this way. Early twelf th-century pottery was found during the excavations, although none of the residential areas can be dated to that period. The start of intensive cultivation and consequent occupation occurred only towards the end of the twelfth century af ter an initial period of pastoralism on the newly reclaimed marginal land. Most of the residential areas date to the late twelf th to fourteenth centuries, although not all were settled contemporaneously: the occupation shifted from site $G$ to $F$ in the fourteenth century, whereas sites $C$ and $G$ were apparently in use at the same general date. Site D is probably another residential area, judging by the small size of the nearby enclosures, its position close to the line of one of the trackways, and the quantities of domestic ref use surrounding it. If this is correct, then three sites $(C, D, G)$ were occupied within the 18 ha area during the thirteenth to early fourteenth centuries.

Later settlements at Lydd are far fewer. Occupation at sites A, B, C, D and G probably ceased no later than the early part of the fourteenth century, and site $\mathrm{F}$ is the only one so far discovered at the quarry that spans the fourteenth to early fifteenth centuries. It is possible that further sites of this period lie just outside the excavated area, although it is known from documentary sources that there was a reduction in the population on the marsh during this period. The fifteenth to early sixteenth centuries are represented by only one activity area (E) that may, however, have been residential, together with a few outlying features. More material of this period has been found in the final infilling of several of the field ditches across the whole area of the quarry.

\section{Economy}

A preliminary assessment of the assemblage of excavated bones has shown a dominance of cattle and sheep/goat, although pig is also well represented. Provisional observations of bones from deposits at Lydd 5 and 6 suggest that many juvenile animals were killed, but the bones from Lydd 1 and 2 suggest that animals were killed mainly when mature. The slaughter of mature rather than juvenile animals is to be expected if commodities such as milk, butter, cheese and wool were important sources of income. Horses and oxen, both of which are represented in the bone assemblage, were used as draught animals.

The charred plant remains recovered during the excavations include a range of cereals, together with other crops such as broad beans and peas. Vetches are also well represented. ${ }^{5}$ Documentary sources

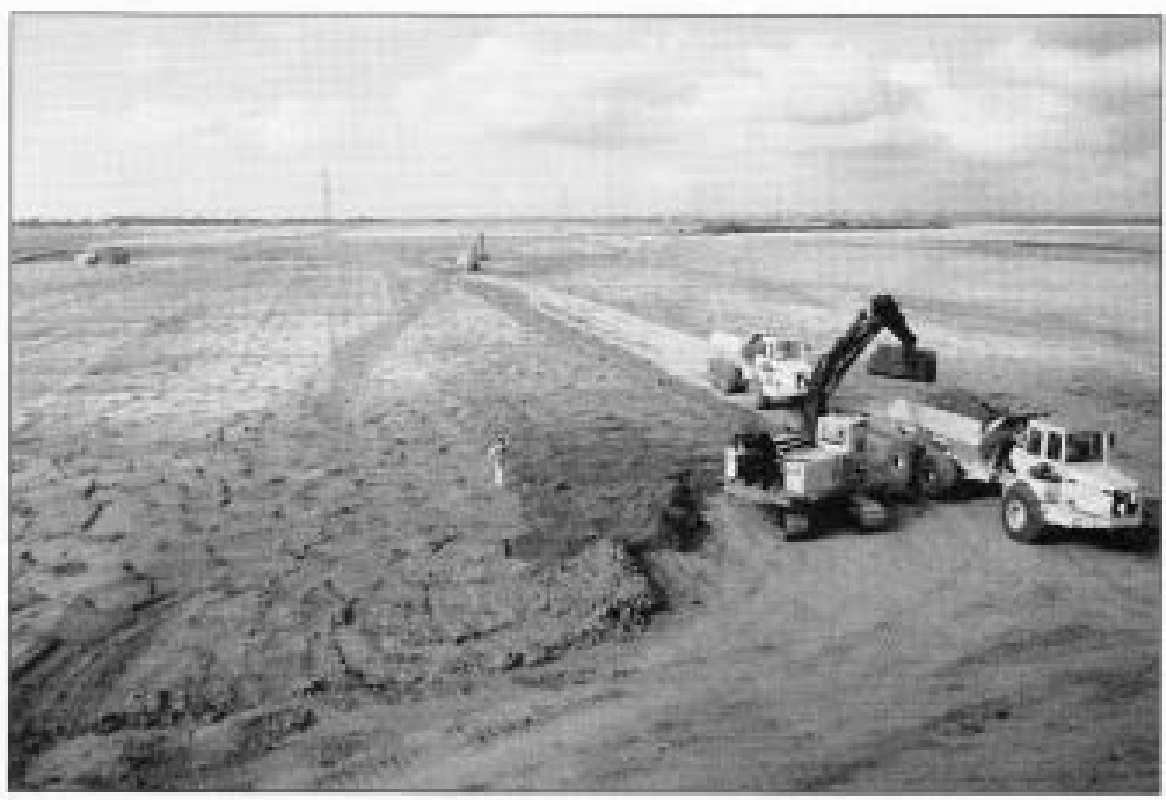

Figure 4 Stripping topsoil during the first phase of excavation (Lydd 1) at Lydd Quarry. were sold at market and the smaller ones consumed directly by the local people.

It is surprising that relatively small quantities of fishbones have been recovered from the excavations, particularly because the thirteenth- to fourteenth-century residential areas, especially site G in Lydd 2, have yielded many fishing weights made of rolled lead. Only one fish hook has been found so far and it is probable that the lead weights were used on hand-thrown nets rather than lines.

\section{Material culture and trade}

The excavations have yielded substantial quantities of pottery from a variety of features. The plain utilitarian nature of the pot sherds, with few imported wares of high quality, reflects the apparently low social status of the excavated sites and their geographical isolation. Judging from suggest that they were grown for animal fodder, a practice common in medieval England. ${ }^{6}$ Interestingly, the most recent sample, dated to AD 1680-1720, contains no evidence for cereal crops but only seeds of wild plants thatgrow on damp grassland and waste areas.

It appears that the mixed arable/pastoral farming economy was supplemented by the exploitation of the rich natural resources of the marsh and its immediate environs, for both food and other materials. Large quantities of marine shell are present on nearly all the occupation sites, particularly those dated to the thirteenth and fourteenth centuries. The dominant species by number of remains found is cockle. However, calculation of the meat weight of the species suggests that oyster provided as much food as cockle, despite the smaller quantities of oyster shell found. The cockles are in general small and their size appears to decrease throughtime, which suggests either overexploitation of the resource or that the larger specimens 


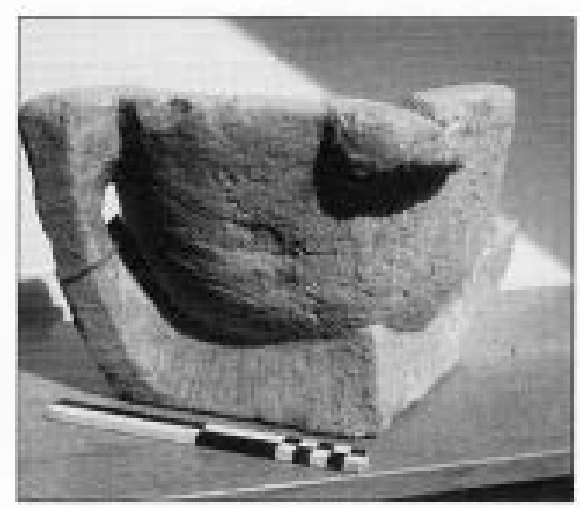

Figure 5 A medieval (thirteenth to fourteenth century) limestone mortar excavated at Lydd 6. It is likely to have come from near Folkestone (scale bar $20 \mathrm{~cm}$ ).

the pottery and the stone artefacts (Fig. 5), the trade network associated with all the occupation sites appears to have been directed primarily towards the east. Most trade goods probably reached the settlements via the port of New Romney, some $5 \mathrm{~km}$ to the northeast, because land passage across the marsh is likely to have been slow and difficult, particularly in winter. Material from farther afield, such as grindstones (querns) made of volcanic lava from Germany, and pottery from France and Scarborough in Yorkshire, are also likely to have come via New Romney.

\section{Conclusion: medieval reclamation and colonization on the marsh}

The excavation of large areas of the medieval landscape at Lydd Quarry has demonstrated the complexity of its evolving pattern of settlement and land use. Full analysis of the massive body of excavated data from the quarry will allow more complete interpretation of the progressive development of the field system, the residential and activity areas and the local economy, which can then be compared archaeologically with other marshlands and contrasted with dryland areas. Meanwhile a preliminary account of landscape evolution in the area of Lydd Quarry can be put forward.

The ditched field system appears to have been established in the first half of the twelfth century. The excavated area must be viewed as but a small part of the reclamation that occurred on Romney Marsh during this and the following centuries. The natural shingle ridges southwest of Lydd offered convenient drier points of access from which to lay out and excavate a system of drainage ditches. As a result, the field system took on the orientation of the natural topography of the area: a pattern that survives to the present day. The presence of sinuous natural drainage channels in some of the lower-lying areas between the ridges and the limited palaeoenvironmental evidence indicate that very wet conditions prevailed when the field system was initiated. However, these natural channels were incorporated, with some modification, into the system of regular ditches as they were established.

Apparently the area was not permanently occupied while the ditch system was being created, nor indeed for a little time thereafter. It is probable that the newly drained area was still regarded as marginal land and that it was used primarily for pasture, with little intensive human activity taking place there. However, during the late twelfth and thirteenth centuries, small low-status habitation sites were established within the field system. It is uncertain whether this was the result of the improvement of the land or of increasing demographic pressures, or both.

The archaeological evidence suggests that farmsteads were closely spaced at this time, with an estimated density of one residential site to 6 ha of land. All these sites were adjacent to the trackways that followed the shingle ridges. The forms of individual farmsteads varied, butfew clear traces of their structural plans have survived. However, the main dwellings were probably small timber-frame buildings constructed on low stone walls, and their roofs would have been thatched with straw or reeds. There would have been other insubstantial ancillary structures on the residential sites.

The farmsteads continued in use throughout the thirteenth century and into the early fourteenth. During this period the surrounding ditch system was maintained, with existing ditches being repeatedly cleaned. Modifications were also sporadically made, for example by creating new ditches that subdivided some existing fields. This subdivision may have been undertaken to improve drainage and it may therefore be an indication of increasing arable cultivation. Associated with the farmsteads, but set at some distance from them, were several activity areas. These were usually demarcated by small enclosures where domestic and probably animal waste was dumped, and they may have been collection points for manure prior to it being spread on the fields.

During this period, mixed farming was practised. Livestock included cattle, sheep and pigs, and the crops appear to have been predominantly cereals, beans, peas and vetches. How much of the arable crop was grown for human as opposed to livestock consumption is uncertain at present, but, following further analysis of the excavated material, it may be possible to identify changes between pastoralism and arable cultivation and in the types of crops and livestock raised. The peasant farmers of the thirteenth and fourteenth centuries supplemented their agricultural produce by exploiting the rich local natural resources. These ranged from shellf ish from the coast to woodland resources and stone from the Weald. Lydd and New Romney would have served as centres for selling produce and purchasing of manufactured goods.
During the later fourteenth century the number of farmsteads in the area of Lydd Quarry decreased. This appears to be the start of a general trend of depopulation on the marsh as a whole, which continued throughout the fifteenth century to the mid-sixteenth. The field system was still being modified during this period, with several ditches being infilled or allowed to silt up. The trend was towards the creation of larger and more regular fields, possibly as a result of both the decrease in human population and an increase in pastoralism.

Much archaeological work is still required on Romney Marsh to address both local and wider issues of medieval occupation and resource exploitation. When the excavations at Lydd Quarry have been fully analyzed, they will provide a large body of data of great value in formulating new research agendas and interpreting the results of future excavations.

\section{Notes}

1. See Exploring our past: strategies for the archaeology of England, p. 39 (London: English Heritage, 1991).

2. Brett Gravel Ltd has funded all phases of work at the site.

3. For further information on Romney

Marsh, including the excavations at Lydd Quarry, the reader is referred to the work of the Romney Marsh Research Trust and to the three following monographs published by the Oxford University Commit tee for Archaeology:

J. Eddison \& C. Green (eds), Romney Marsh: evolution, occupation, reclamation $(24,1988)$

J. Eddison (ed.), Romney Marsh: the debatable ground $(41,1995)$.

J. Eddison, M. Gardiner, A. Long, Romney Marsh: environmental change and human occupation in a coastal lowland $(46,1998)$.

4. A. Reeves, Reclamation and cultivation: further earthworks survey on Romney Marsh. Unpublished report, Romney Marsh Research Trust, Canterbury, 1996.

5. Vetches are plants of the pea family, often grown for animal fodder. They are very difficult to identify archaeobotanically. The only species identified at Lydd is the common vetch, Vicia sativa.

6. B. Campbell, "The diffusion of vetches in medieval England", Economic History Review [2nd series] 41, 193-208, 1988. 